\title{
Biocontrol of Soft Rot: Confocal Microscopy Highlights Virulent Pectobacterial Communication and Its Jamming by Rhodococcal Quorum-Quenching
}

\author{
Andrea Chane, ${ }^{1}$ Corinne Barbey, ${ }^{1,2}$ Magalie Robert, ${ }^{1}$ Annabelle Merieau, ${ }^{1}$ Yoan Konto-Ghiorghi, ${ }^{1}$ \\ Amélie Beury-Cirou, ${ }^{2,3}$ Marc Feuilloley, ${ }^{1}$ Miroslav Pátek, ${ }^{4}$ Virginie Gobert, ${ }^{2,3}$ and Xavier Latour ${ }^{1 \dagger}$ \\ ${ }^{1}$ Laboratoire de Microbiologie Signaux et Microenvironnement (LMSM EA 4312)-Normandie Université-LMSM, 55 rue \\ Saint-Germain, 27000 Evreux, France and Structure Fédérative de Recherche Normandie Végétale 4277 \\ ${ }^{2}$ Seeds Innovation Protection Research and Environment, Route de la petite chaussée, 76110 Bretteville du Grand-Caux \\ and Rue des Champs Potez, 62217 Achicourt, France \\ ${ }^{3}$ French Federation of seed potato growers (FN3PT/RD3PT), 43-45 rue de Naples, 75008 Paris, France \\ ${ }^{4}$ Institute of Microbiology of the CAS, v.v.i. Vídeňská 1083, CZ-14220 Praha 4, Czech Republic
}

Accepted 15 January 2019.

\begin{abstract}
Confocal laser-scanning microscopy was chosen to observe the colonization and damage caused by the soft rot Pectobacterium atrosepticum and the protection mediated by the biocontrol agent Rhodococcus erythropolis. We developed dual-color reporter strains suited for monitoring quorum-sensing and quorum-quenching activities leading to maceration or biocontrol, respectively. A constitutively expressed cyan or red fluorescent protein served as a cell tag for plant colonization, while an inducible expression reporter system based on the green fluorescent protein gene enabled the simultaneous recording of signaling molecule production, detection, or degradation. The dual-colored pathogen and biocontrol strains were used to coinoculate potato tubers. At cellular quorum, images revealed a strong pectobacterial quorum-sensing activity, especially at the plant cell walls, as well as a concomitant rhodococcal quorum-quenching response, at both the singlecell and microcolony levels. The generated biosensors appear to be promising and complementary tools useful for molecular and cellular studies of bacterial communication and interference.
\end{abstract}

Pectinolytic bacteria belong to Gram-negative genera Pectobacterium and Dickeya. They cause widespread damage to potato, one of the world's major crops, and numerous vegetable crops in the field and during storage or transit (Charkowski et al. 2012; Czajkowski et al. 2015; Reverchon and Nasser 2013). Among these pectinolytic bacteria, members of the Pectobacterium atrosepticum species infect potato plants in

${ }^{\dagger}$ Corresponding author: X. Latour; xavier.latour@univ-rouen.fr

A. Chane and C. Barbey contributed equally to this work.

Funding: This research was supported by grants from French institutions (Ministère de l'Enseignement Supérieur, de la Recherche et de l'innovation, Régions Bretagne, Normandie, \& Pays de Loire, and the Evreux Portes de Normandie agglomération), the VASI network, the Pôle de Compétivité Valorial, and FEDER (European Union). Works are related to COST 631 action: Understanding and Modeling Plant-Soil Interactions in the Rhizosphere Environment (UMPIRE).

The author(s) declare no conflict of interest.

(c) 2019 The American Phytopathological Society cool and temperate countries, causing tuber soft rot and blackleg disease of the plant stem (Pérombelon 2002; Smadja et al. 2004b). Basic knowledge on the regulation of virulence in $P$. atrosepticum showed pathogen communication via quorumsensing (QS) signals to be a crucial step for the expression of virulence and the onset of disease symptoms (Barnard and Salmond 2007; Liu et al. 2008). QS systems are cell-to-cell communication mechanisms based on both the synthesis and perception of signaling molecules, the best known of which belong to the $N$-acyl-homoserine lactone (AHL) family (Papenfort and Bassler 2016). They play a key role in the pathogenicity of many agronomically relevant pathogens (Cha et al. 1998; von Bodman et al. 2003). When a threshold population density is reached (i.e., quorum), the corresponding threshold signal concentration can be sensed and the expression of the target genes regulated. AHL molecules are synthesized by LuxI synthases and interact with one or more of their cognate receptors, belonging to the LuxR family. According to the position of its binding site on DNA, the LuxR response regulator can act as an activator or a repressor of the target gene transcription, leading to coordinated behavior (Papenfort and Bassler 2016). In P. atrosepticum, the LuxR analog VirR acts as a global repressor protein that inhibits the production of plant cell-wall-degrading extracellular enzymes (PCWDEs) (Barnard and Salmond 2007; Burr et al. 2006). In other words, the critical AHL concentration induces a massive and synchronized production of PCWDE.

Our previous findings enabled us to determine the specific contribution of QS throughout the chronology of soft rot tuber events due to P. atrosepticum (Smadja et al. 2004a). The key role of pectobacterial QS communication led to the development of a biocontrol strategy based on the screening of environmental bacteria capable of catabolizing QS signals (Dessaux et al. 2016; Jafra et al. 2006). We isolated the Rhodococcus erythropolis strain R138, a Gram-positive biocontrol agent able to effectively degrade a wide range of AHLs (Afriat et al. 2006; Cirou et al. 2007) and to suppress the disease in hydroponic and field culture conditions (Cirou et al. 2011a,b). The quorumquenching (QQ) nature of this protection was demonstrated in planta and mainly involves a new pathway (Barbey et al. 2013). This pathway requires the expression of the QS signal degradation $(q s d)$ operon which is regulated by a TetR-like transcriptional repressor named QsdR (El Sahili et al. 2015; Latour 
et al. 2013). In the absence of QS signal, the QsdR repressor binds to the promoter region of the qsd operon switching off the pathway. When AHL signals are present in a cellular environment, their homoserine lactone ring binds to QsdR, thereby changing its conformation. Thus, QsdR cannot bind to the promoter region, inducing derepression of the $q s d$ operon expression (Barbey et al. 2018). This leads to the production of QsdA and QsdC enzymes involved in the lactone ring and acyl chain catabolism of AHLs, respectively (Barbey et al. 2018).

Today, understanding the regulatory mechanisms of both pectobacterial QS and rhodococcal QQ provides the opportunity to monitor these molecular interactions in situ. Indeed, the use of promoter-probe vectors carrying various reporter genes represents an elegant approach for the analysis of gene expression and the role of regulatory proteins (Bloemberg 2007; Phillips 2001; Rochat et al. 2010). In this study, we generated $P$. atrosepticum and $R$. erythropolis biosensors capable of coexpressing two fluorescent proteins (Chalfie et al. 1994). The gene encoding the first fluorophore was expressed from a constitutive promoter as a cell tag, while the second was used as a LuxR- or QsdR-based reporter system for monitoring QS and QQ activity, respectively. These biosensors were used to inoculate potato tubers in order to simultaneously visualize tuber colonization in addition to AHL production, detection, and degradation. The images obtained in epifluorescence and confocal laser-scanning microscopy (CLSM) were analyzed with respect to the colonization patterns, amount of AHL, and rotting symptoms. They revealed intense QS and QQ activities which could be perceived as an "informational war in tuberspace" between the Gram-negative pectobacteria and its Grampositive rhodococcal antagonists.

\section{RESULTS}

Construction of pectobacterial biosensors, deprived or not of their own QS communication, for the detection of QS signals.

P. atrosepticum strain CFBP6276 is a virulent AHL producer strain (see Materials and Methods section). Hereafter, for simplicity, it is referred to as $\mathrm{Pa}$-QS+. The $\mathrm{Pa}$-QS+ chromosome (4.8 Mbp) carries a unique luxI homolog gene (Kwasiborski et al. 2013). Because the $P a-Q S+$ virulence is under the control of AHL signals, an avirulent mutant was obtained by a random transposon mutagenesis inactivating luxI (Latour et al. 2007). Because this strain does not produce AHL signals, it is referred to as $P a-Q S-$. The cyan fluorescent protein $(c f p)$ gene was cloned into the stable broad-host-range vector pME6000 under the constitutive promoter $\mathrm{P}_{l a c}$ (Maurhofer et al. 1998) to tag both $P$. atrosepticum strains. In order to monitor the occurrence of AHL, a Vibrio fisheri lux-based reporter system was added into the pME6000-cfp vector. This consists of a transcriptional fusion between the luxI promoter and $g f p_{a s v}$ gene, under the control of the luxR gene (Andersen et al. 2001). In the presence of AHLs, the quorum sensor LuxR binds to the luxI promoter region and activates the transcription of the green fluorescent protein $(g f p)$ gene. This reporter gene encodes an unstable GFP derivative $\left(\mathrm{GFP}_{\mathrm{ASV}}\right.$ containing alanine, serine, and valine) at the $\mathrm{C}$ terminus.

Dual-tagged $\mathrm{Pa}$-QS+ and $\mathrm{Pa}$-QS- cells have the same growth kinetics when cultivated in a minimal medium containing polygalacturonic acid (PGA) as the sole source of carbon and energy (Fig. 1A). They exhibited identical growth characteristics as the CFBP6276 parental strain (data not shown). Cells were examined by CLSM at two excitation and emission wavelengths; when images were recorded at 405 and $477 \mathrm{~nm}$ (blue channel), both $P$. atrosepticum strains formed coccobacilli emitting a sky-blue fluorescence throughout their growth. In addition, when studied at 488 and $509 \mathrm{~nm}$ (green channel), only the $P a-\mathrm{QS}+$ strain produced a bright-green fluorescence that masked the blue one (Fig. 1B), whereas the Pa-QS- strain produced blue fluorescence (Fig. 1B2). This fluorescence started in the exponential growth phase and remained throughout the stationary phase. The production of bright-green fluorescence was restored in the $\mathrm{Pa}-\mathrm{QS}-$ strain as soon as a minimum AHL concentration of $10 \mathrm{nM}$ was added (Fig. 1B3).

\section{Construction of rhodococcal biosensor} for detection and degradation of QS signals.

$R$. erythropolis is a Gram-positive Actinobacterium exhibiting a strong catabolic potential, even at cool temperatures (de Carvalho and da Fonseca 2005). The mcherry gene was cloned into the pEPR1 vector under the strong constitutive Corynebacterium glutamicum promoter P-45 (Knoppová et al.

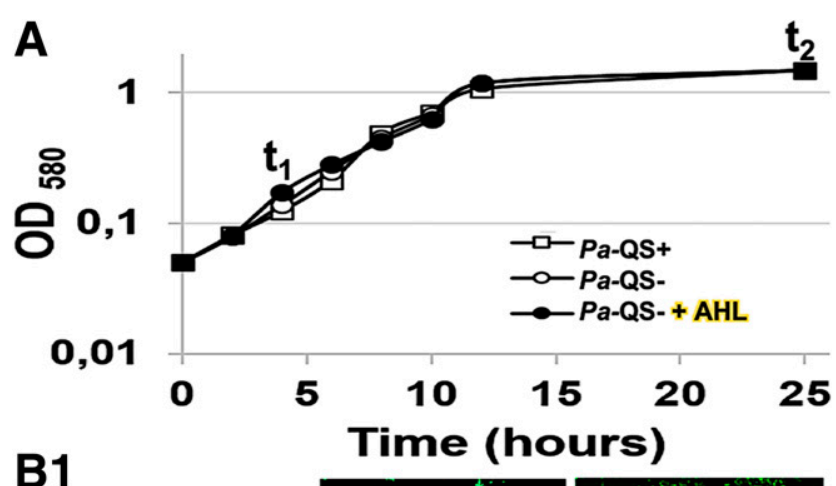

B1
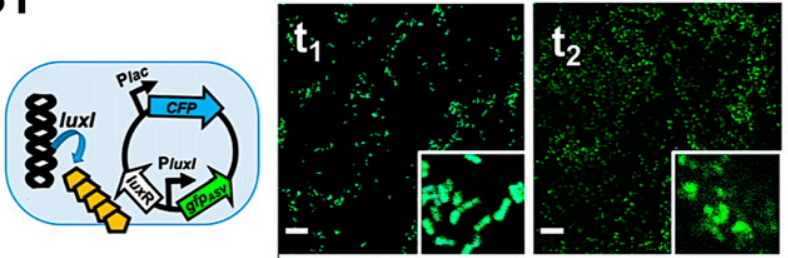

B2
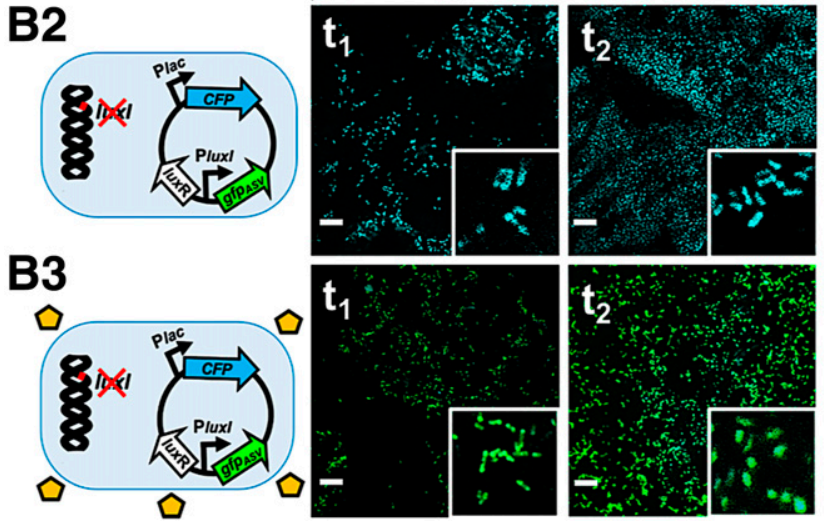

Fig. 1. A, Growth kinetics and B, confocal microscopy images of Pectobacterium atrosepticum CFBP6276 pathogen dual-colored strains. Bacterial cells were grown in polygalacturonic acid minimal medium and harvested after $4 \mathrm{~h}\left(\mathrm{t}_{1}\right)$ and $24 \mathrm{~h}\left(\mathrm{t}_{2}\right)$ of incubation for confocal microscopy analysis. The $P$. atrosepticum pME6000-luxR-PluxI::gfp ${ }_{A S V}$ cyan fluorescent protein (CFP) strain ( $\mathrm{Pa}-\mathrm{QS}+, \mathrm{B} 1$ panel) was incubated in the absence of exogenous 3-oxo- $\mathrm{C}_{8}$-HSL molecules whereas its mutant luxI, lacking quorum-sensing signal synthesis ( $\mathrm{Pa}-\mathrm{QS}-$-), was cultivated in the absence or presence of $10 \mathrm{nM}$ exogenous 3 -oxo- $\mathrm{C}_{8}$-HSL molecules (B2 and B3 panels, respectively). The map of each designed vector and 3 -oxo- $\mathrm{C}_{8}-\mathrm{HSL}$ origin (yellow pentagons) is indicated. $\mathrm{OD}_{580}=$ optical density at $580 \mathrm{~nm}$ and AHL $=N$-acyl-homoserine lactone. A close-up of some cells is proposed in the lower right window. Fluorescence images representative of three independent experiments were combined in the blue and green channels; scale bar represents $10 \mu \mathrm{m}$. For growth curves, each value is the mean of three replicates, with the standard deviation indicated. 
2007; Pátek et al. 1996) to tag R. erythropolis R138 cells. This promoter was also shown to be highly functional in $R$. erythropolis (Veselý et al. 2003). To investigate AHL degradation, a $\mathrm{P} q s d:: g f p_{\mathrm{uv}}$ transcriptional fusion between the $q s d$ promoter and $g f p$ reporter gene under the regulation of QsdR was introduced into the pEPR1-mCherry vector (Barbey et al. 2018). This construction, pEPR1-qsdR-P $q s d:: g f p_{u v}-m$ Cherry, mimics the regulation system of qsd operon expression. Thus, the construct allows the monitoring of qsd promoter and QsdR regulator activities.

When cultivated in a hexanoate minimal medium, rhodococcal cells have the same growth kinetic in the presence or absence of 3-oxo- $\mathrm{C}_{8}$-HSL (Fig. 2A). CLSM revealed "nocardioform" rhodococci (i.e., cells with a mycelial growth and fragmentation into rod-shaped or coccoid elements) (Bell et al. 1998). No morphological difference of $R$. erythropolis cells was observed under the two cultivation conditions. Bacterial cells remained uniformly red throughout the entire cultivation in the absence of signaling molecules (Fig. 2B1). The addition of a minimal concentration of $1 \mu \mathrm{M}$ of 3 -oxo- $\mathrm{C}_{8}$-HSL induced a change in fluorescence from red to yellow-greenish fluorescence (due to the combination of mCherry and $\mathrm{GFP}_{\mathrm{UV}}$ protein fluorescence) from $2 \mathrm{~h}$ onward (Fig. 2B2). Due to Pqsd::gfp $p_{\mathrm{uv}}$ transcriptional fusion, this fluorescence change revealed not only AHL detection but also derepression of qsd operon expression. For this reason, this $R$. erythropolis AHL quencher strain is referred to as $R e-\mathrm{QQ}+$.

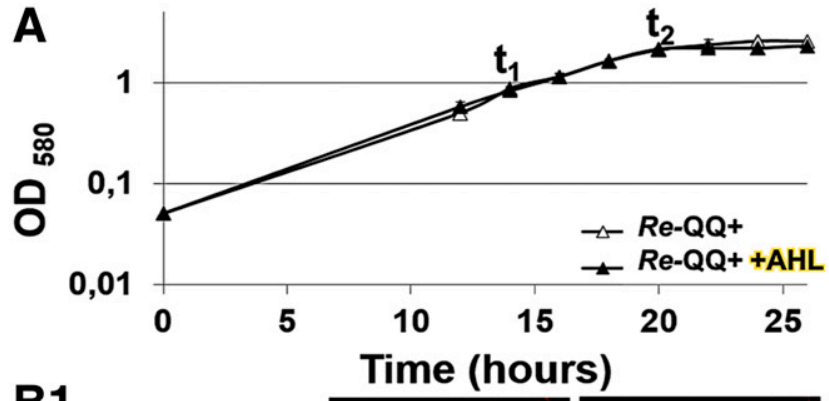

B1

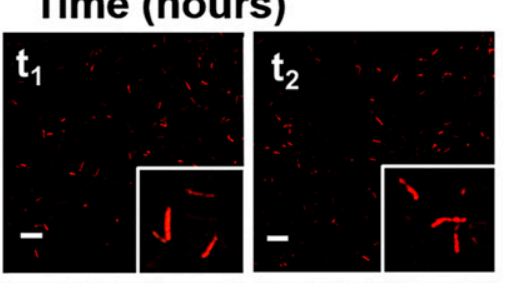

B2
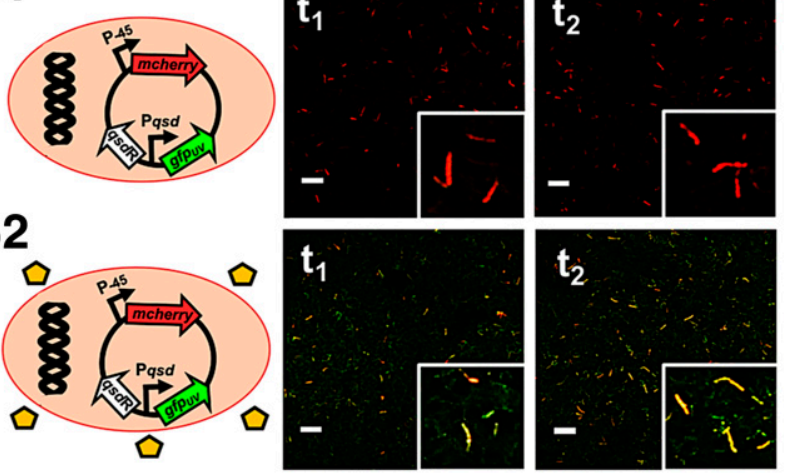

Fig. 2. A, Growth kinetics and B, confocal microscopy images of Rhodococcus erythropolis R138 biocontrol agent dual-colored strain. Bacterial cells were grown in hexanoate minimal medium and harvested after $14 \mathrm{~h}$ $\left(\mathrm{t}_{1}\right)$ and $20 \mathrm{~h}\left(\mathrm{t}_{2}\right)$ of incubation from culture of the $R$. erythropolis pEPR1$q s d R-\mathrm{P} q s d:: g f p_{\mathrm{uv}}-m C h e r r y$ strain $(R e-\mathrm{QQ}+)$ in the absence or presence of $1 \mu \mathrm{M} 3$-oxo- $\mathrm{C}_{8}$-HSL molecules added $2 \mathrm{~h}$ before $\mathrm{t}_{1}$ (B1 and B2 panels, respectively). The map of each designed vector and 3-oxo- $\mathrm{C}_{8}-\mathrm{HSL}$ origin (yellow pentagons) is indicated. $\mathrm{OD}_{580}=$ optical density at $580 \mathrm{~nm}$ and AHL $=N$-acyl-homoserine lactone. A close-up of some cells is proposed in the lower right window. Fluorescence images representative of three independent experiments were combined in the green and red channels; scale bar represents $10 \mu \mathrm{m}$. For growth curves, each value is the mean of three replicates with the standard deviation indicated.
Colonization of wounded tuber by $P$. atrosepticum pathogen, bacterial QS communication, and subsequent soft rot.

Potato tubers were wounded and infected by intramedulla injection with a suspension of dual-colored $P a-Q S+$ cells. This potato tuber test enabled the easy determination of both the bacterial population density and the presence of macerated tissue up to 14 days after inoculation (Smadja et al. 2004a). This pathosystem has been widely used and pointed out a key timing of the pathogenic cycle (i.e., 2 days postinoculation [dpi]) (Barbey et al. 2013; Crépin et al. 2012b). Considering these assay conditions, it is possible to distinguish two phases of the disease. Between the inoculation and 2 dpi, the pathogen population increased by more than two orders of magnitude,
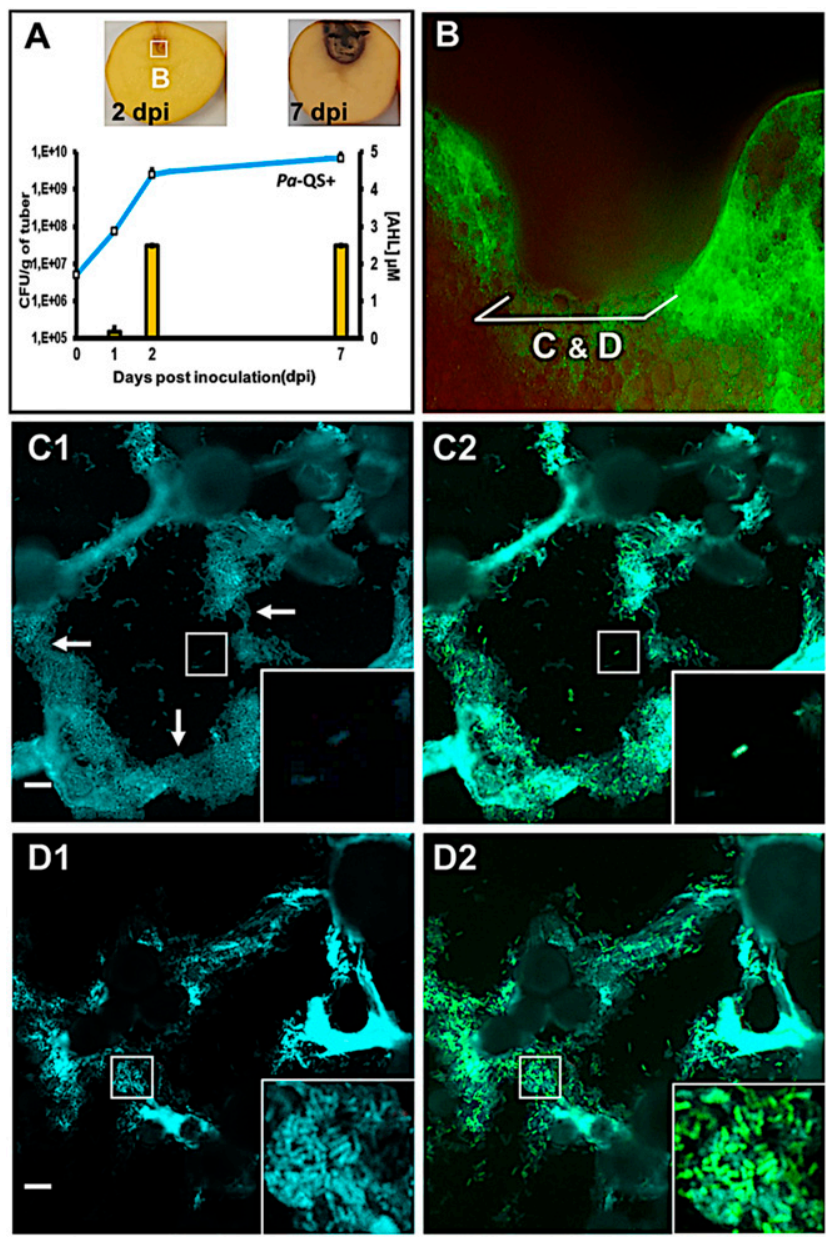

Fig. 3. In situ distribution and quorum-sensing (QS) activity of Pectobacterium atrosepticum soft-rot pathogen. Potato tubers were inoculated axenically with the $P$. atrosepticum CFBP6276 (Pa-QS+) dual-colored strain. The constitutively produced cyan fluorescent protein served as a cell tag (blue fluorescent cells), whereas a reporter fusion based on the green fluorescent protein enabled the simultaneous recording of the production and presence of $\mathrm{N}$-acyl-homoserine lactone (AHL) signaling molecules (green fluorescent cells). A, Tuber temporal colonization, AHL amount, and symptoms at 2 and 7 days postinoculation (dpi), For lines and bars, each value is the mean of three replicates with the standard deviation indicated. B, Epifluorescence observation of the bottom surface of the wound at 2 dpi using images combined in green and red channels. $\mathbf{C}$ and $\mathbf{D}$, Confocal microscopy observation of the bottom surface of the wound at $2 \mathrm{dpi}$ with ultrathin cross-section. Images were combined in the blue and red channels (C1 and D1), supplemented with the green channel (C2 and D2). A close-up of isolated (C) or clustered (D) cells is proposed in the lower right window. White arrows indicate breakdown areas of the plant cell wall associated with a strong bacterial hydrolysis activity. Scale bar represents $10 \mu \mathrm{m}$. 
reflecting the primary invasion stage (Fig. 3A). At the end of this stage, the bacterial population reached the quorum, a population producing a $2.5-\mu \mathrm{M}$ threshold concentration of signaling molecules measured in the tuber wound under our assay conditions. This threshold density provokes the transition to the maceration stage, where the bacterial growth rate decreases while an induction of the rotting symptoms is easily perceptible 7 days (Fig. 3A). The key date of transition between the two phases $(2 \mathrm{dpi})$ was chosen for all microscopic observations.
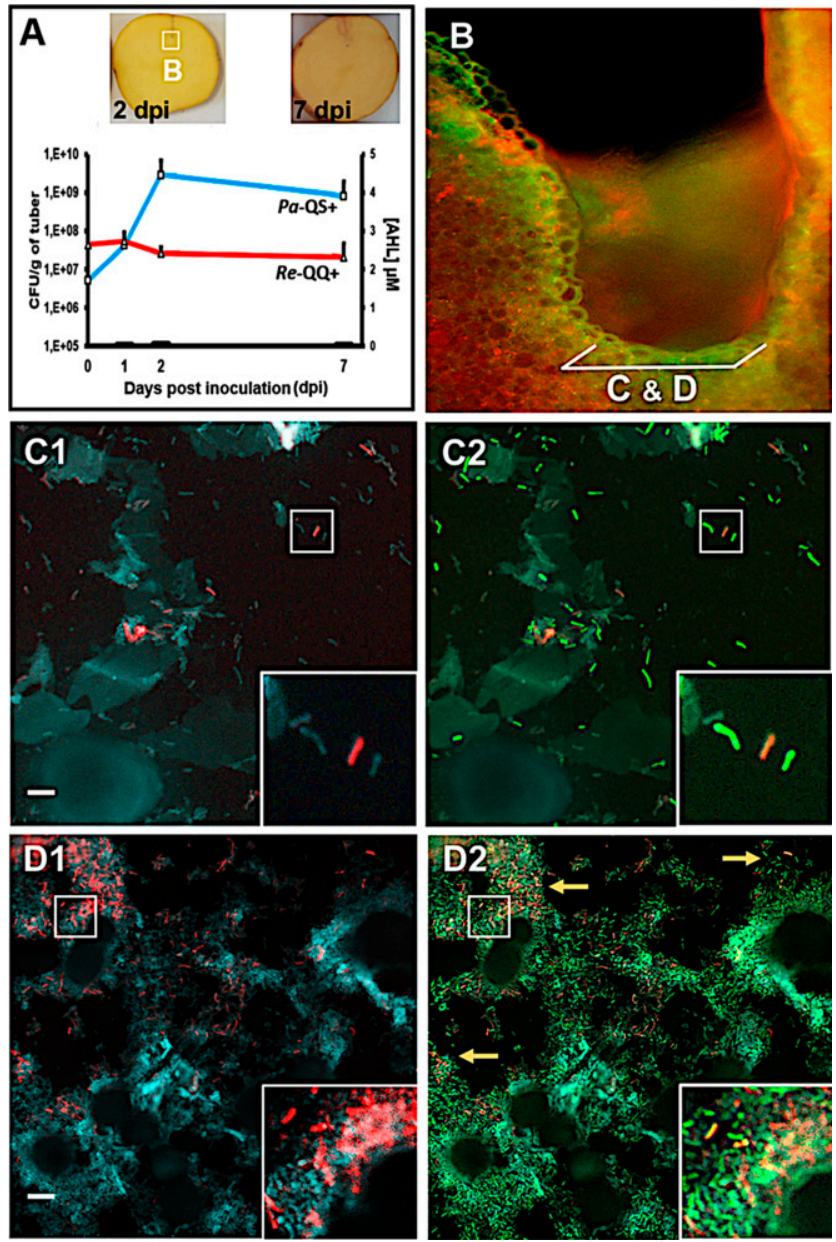

Fig. 4. In situ distribution, quorum-sensing (QS) activity of Pectobacterium atrosepticum soft-rot pathogen, and quorum-quenching (QQ) activity of Rhodococcus erythropolis biocontrol agent. Potato tubers were coinoculated axenically with the $P$. atrosepticum CFBP6276 ( $P a-Q S+)$ and $R$. erythropolis R138 (Re-QQ+) dual-colored strains; the constitutively produced cyan or mCherry fluorescent protein served as a cell tag for $\mathrm{Pa}$-QS+ (blue fluorescent cells) and $R e-\mathrm{QQ}+$ (red fluorescent cells), respectively, whereas a reporter fusion based on the green fluorescent protein enabled the simultaneous recording of the production and presence of $\mathrm{N}$-acyl-homoserine lactone (AHL) signaling molecules for $\mathrm{Pa}-\mathrm{QS}+$ (green fluorescent cells) or the simultaneous recording of AHL detection and degradation by $R e-\mathrm{QQ}+$ (yellow to amber fluorescent cells). A, Tuber temporal colonization, AHL amount, and symptoms at 2 and $7 \mathrm{dpi}$. For lines and bars, each value is the mean of three replicates with the standard deviation indicated. B, Epifluorescence observation of the bottom surface of the wound at $2 \mathrm{dpi}$ using images combined in green and red channels. $\mathbf{C}$ and $\mathbf{D}$, Confocal microscopy observation of the bottom surface of the wound at $2 \mathrm{dpi}$ with ultrathin cross-section with low (C) and high (D) cellular density. Images were combined in the blue and red channels (C1 and D1), supplemented with the green channel (C2 and D2). A close-up of isolated or clustered cells is proposed in the lower right window. Yellow arrows indicate a hot spot containing a mixed ( $P a-Q S+$ plus $R e-Q Q+)$ cluster with both strong QS and QQ activities. Scale bar represents $10 \mu \mathrm{m}$.
Inverted microscopy was used for primarily looking at living bacteria and plant tissue. Infected tubers were cut and tuber slices were analyzed with epifluorescence microscopy (EM). Here, only red and green channels were used to record bacterial cell emission, because a negligible red and green tuber background fluorescence was observed (Fig. 3B). In contrast, a strong autofluorescence emitted by the potato thick tissue was recorded under the blue channel (data not shown). At 2 dpi, a significant green fluorescence covering a large area of the wound was observed, enabling the in situ monitoring of the
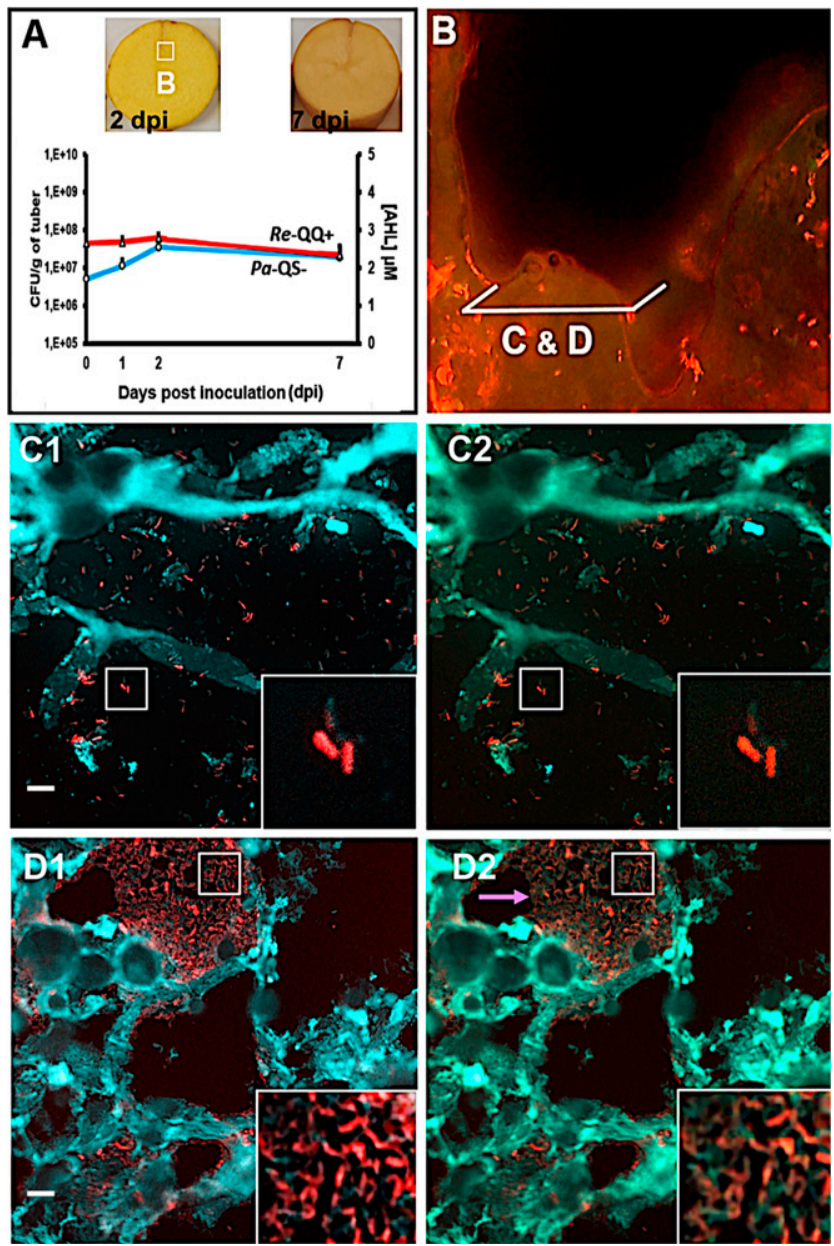

Fig. 5. In situ distribution, quorum-sensing (QS) activity of Pectobacterium atrosepticum avirulent pathogen, and quorum-quenching (QQ) activity of Rhodococcus erythropolis biocontrol agent. Potato tubers were coinoculated axenically with the $P$. atrosepticum CFBP6276 luxI mutant ( $P a-Q S-)$ and $R$. erythropolis $\mathrm{R} 138$ ( $R e-\mathrm{QQ}+$ ) dual-colored strains; the constitutively produced cyan or mCherry fluorescent protein served as a cell tag for $\mathrm{Pa}$ QS- (blue fluorescent cells) and $R e-\mathrm{QQ}+$ (red fluorescent cells), respectively, whereas a reporter fusion based on the green fluorescent protein enabled the simultaneous recording of the production and presence of $\mathrm{N}$-acyl-homoserine lactone (AHL) signaling molecules for $\mathrm{Pa}$-QS- (green fluorescent cells), or the simultaneous recording of AHL detection and degradation by $R e-\mathrm{QQ}+$ (yellow to amber fluorescent cells). A, Tuber temporal colonization, AHL amount and symptoms at 2 and 7 days postinoculation (dpi). For lines and bars, each value is the mean of three replicates with the standard deviation indicated. B, Epifluorescence observation of the bottom surface of the wound at 2 dpi using images combined in green and red channels. $\mathbf{C}$ and $\mathbf{D}$, Confocal microscopy observation of the bottom surface of the wound at 2 dpi with ultrathin crosssection with low (C) and high (D) cellular density. Images were combined in the blue and red channels (C1 and D1), supplemented with the green channel (C2 and D2). A close-up of isolated or clustered cells is proposed in the lower right window. The purple arrow indicates a mixed $(\mathrm{Pa}-\mathrm{QS}-$ plus $R e$-QQ+) cluster with no QS or QQ activities. Scale bar represents $10 \mu \mathrm{m}$. 
extensive AHL production by $P a-Q S+$ cells (Fig. 3B). This confirms the strong colonization highlighted by bacterial counts (Fig. 3A). Ultrathin cross-sections were made at the bottom surface of the pith's wound and were analyzed by CLSM. For each set of microscopy observation conditions, two sets of observations were recorded showing low and high bacterial densities and a focus on a single-cell (Fig. 3C) or a microcolony (Fig. 3D) structure. The first panel is composed of images combined in the blue and red channels to locate both the CFP-tagged pathogen and the mCherry-tagged biocontrol agent required for the experiments described below. In these conditions, a slight blue autofluorescence reveals the cellular structure of the pith; translucent parenchyma cells, sometimes containing opaque and oval amyloplasts, are delineated by their fluorescent cell wall, and sometimes separated by intercellular spaces (these observations are the same in Figures 3, 4, and 5). Detailed studies on the localization of $\mathrm{Pa}-\mathrm{QS}+$ cells in the pith showed that bacteria were present both inter- and intracellularly. However, they were mainly aggregated and embedded in the more or less hydrolyzed plant cell wall (Fig. 3C1 and D1). The second set adds the green channel observation to the previous images, highlighting both potential green-monitored QS and QQ activities (see next section for the latter). The $\mathrm{Pa}$-QS+ colonization was accompanied by the production of a bright-green fluorescence, reflecting a strong AHL production by both single cells and microcolonies. This fluorescence occurred in the vast majority of but not all cells (Fig. 3C2 versus D2).

\section{Colonization of tuber and interaction between rhodococcal biocontrol agent and $P$. atrosepticum pathogen deprived or not of QS communication.}

When tubers were coinoculated with the $\mathrm{Pa}$-QS+ pathogen and the $R e-\mathrm{QQ}+$ biocontrol agent, only trace amounts of AHL were detected in potato tissues (Fig. 4A). As a consequence, AHL-dependent maceration of the tissues decreased dramatically between 2 and 7 days (Figs. 3A versus 4A). Only a residual colorless maceration was observed around the wound at the end of the experiment in the presence of the plant-protective $R e-\mathrm{QQ}+$ (Fig. 4A, bottom panel). However, the primary invasion stage was always assumed by the pathogen; from the inoculation time to the quorum ( $2 \mathrm{dpi}$ ), the pathogen population increased by two orders of magnitude. Then, it decreased slowly, probably because of a lack of nutrients associated with the nonappearance of symptoms. The biocontrol agent population remained stable over the duration of the experiment (Fig. 4A).

EM confirmed that both the pathogen and the antagonist colonized the tuber wound within 2 dpi (Fig. 4B). This colonization was associated with strong concomitant activities of QS and QQ, the former revealed by the green fluorescence (monitoring the presence of AHL) and the latter by the amber to yellow fluorescence, presumed to be associated with the detection and degradation of these AHLs by Re-QQ+ (Fig. 4B). CLSM observation showed that blue (pathogen) and red (biocontrol agent) fluorescent rod-shaped bacteria were present inside and between pith cells (Fig. 4C1 and D1). Nevertheless, the $R e-\mathrm{QQ}+$ intracellular colonization appears to be associated with the massive presence of the pathogen in altered pith cells, probably due to $\mathrm{Pa}$-QS+ residual damage or the initial wounding (Fig. 4D1). The production of AHL by individual $\mathrm{Pa}$ QS+ single cells or microcolonies (green fluorescent cells) was confirmed even in the presence of the antagonist (Fig. 4C2 and D2). The ability of the biocontrol agent to perceive and degrade these molecules could be monitored at the single-cell level by a typical amber fluorescence, previously observed during in vitro assays in the presence of AHL inducers (Barbey et al. 2018). Thus, it was possible to observe a serendipitous encounter between an active $R e-\mathrm{QQ}+$ single cell ideally located between two $\mathrm{Pa}$-QS+ individuals in the process of communicating (Fig. $4 \mathrm{C} 2$ ). If necessary, this QQ-associated fluorescence could be only isolated and clearly monitored using the green channel (green fluorescent $R e-\mathrm{QQ}+$ cells) (data not shown, to avoid hiding too much detail from the figures). QQ activity was particularly intense inside yellow hot spots that mixed large amounts of $\mathrm{Pa}-\mathrm{QS}+$ and $R e-\mathrm{QQ}+$ cells aggregated on the parenchyma cell wall (Fig. 4D2). Interestingly, whether for single cells or for aggregated cells, the yellow to amber fluorescence reflecting the QQ was only observed when the $R e-\mathrm{QQ}+$ cells were located near the AHL-producing $\mathrm{Pa}$-QS+ cells at a "quenching distance" of a few micrometers (Fig. 4C2 and D2).

When tubers were coinoculated with the $P a-Q S-l u x I$ mutant and the $R e-\mathrm{QQ}+$ biocontrol agent, neither AHL nor maceration were detected in potato tissues, as expected (Fig. 5A). In addition, only a weak invasion stage was observed for the $P a-\mathrm{QS}-$ strain (Fig. 5A). Then, the $P a-Q S-$ and $R e-Q Q+$ populations decreased slightly during an asymptomatic period from 2 to 7 days (Fig. 5A). EM images confirmed the weak tuber colonization of $R e-\mathrm{QQ}+$ (red fluorescence), except for some cavities of wounded tissue, where $R e-\mathrm{QQ}+$ cells may have accumulated. The global location of $\mathrm{Pa}$-QS- CFP-tagged cells was not possible under the optical method using fluorescence (blue channel) due to the previously mentioned substantial tissue autofluorescence. Moreover, no green fluorescence was detected, reflecting the nonexpression of the $g f p_{A S V}$ reporter gene by $P a-Q S-$ cells (Fig. 5B). This confirmed the inability of $P a-Q S-$ bacteria to synthesize AHL and the absence of exogenous AHLs in the pith. The CLSM observation showed that blue (pathogen) and red (biocontrol agent) fluorescent cells were mainly concentrated together in intercellular spaces or in the rare altered pith cells (Fig. 5C and D). Here, microcolonies containing mixed populations of $P a-\mathrm{QS}-$ and $R e-\mathrm{QQ}+$ cells were observed in the cytoplasm rather than on the wall of the pith cell (Fig. 5C1 and D1). In contrast to the observations recorded after the coinoculation of the $\mathrm{Pa}-\mathrm{QS}+$ and $\mathrm{Re}-\mathrm{QQ}+$ strains, we never observed any green fluorescence in $\mathrm{Pa}-\mathrm{QS}-$ cells or yellow or amber fluorescence in $R e-\mathrm{QQ}+$ cells. This is true for $P a$-QS- and $R e-\mathrm{QQ}+$ single cells separated by a few micrometers from each other (i.e., quenching distance) as well as dense cell clusters (Fig. 5C2 and D2).

\section{DISCUSSION}

Promoter-probe vectors carrying fluorescent protein reporter genes were found to be powerful tools to localize and quantify the AHL-based communication of various bacteria (Andersen et al. 2001; Charlesworth et al. 2015; Christensen et al. 2011; Gantner et al. 2006; Riedel et al. 2001; Steidle et al. 2001). In addition, AHL-based QS controls the expression of more than 1,000 genes in P. atrosepticum; hence, up to a quarter of its genome, including most of the virulence factors, the PCWDEs, and their secretion systems (Liu et al. 2008). Therefore, it seems relevant to monitor the AHL production of this bacterium throughout the host invasion. The pME6000 vector was modified to use components of the lux QS system of $V$. fisheri by including a PluxI-gfp $p_{A S V}$ transcriptional fusion under the control of the luxR gene expression. This lux QS system is known to utilize the $N$-(3-oxo-hexanoyl)-L-homoserine lactone (Schaefer et al. 1996) and exhibits the highest sensitivity for this $V$. fisheri signaling molecule (5 nM) (Andersen et al. 2001). However, the reporter system is also responsive to various related AHL molecules, albeit with lower sensitivity (Andersen et al. 2001; Charlesworth et al. 2015; Riedel et al. 2001). This sensitivity also depends on the vector used and the bacterial species in which it was introduced (Steidle et al. 2001). We 
obtained a response with a similar level of sensitivity to detect 3-oxo- $\mathrm{C}_{8}$-HSL $(10 \mathrm{nM})$, showing that the lux QS system carried by the pME6000 is effective for the fine monitoring of 3-oxo$\mathrm{C}_{8}$-HSL. Finally, the choice of the AHL-reporter cassette is also justified by the high rate of $\mathrm{GFP}_{\mathrm{ASV}}$ protein turnover (Andersen et al. 2001; Steidle et al. 2001). Because the $\mathrm{GFP}_{\text {ASv }}$ produced by a sensor strain is short lived, the green fluorescence reflects a fairly recent AHL induction of $g f p_{A S V}$ gene expression (Gantner et al. 2006). Therefore, it can monitor a transient communication.

The $\mathrm{Pa}$-QS+ and $\mathrm{Pa}$-QS- sensors have the same fitness when cultivated in a PGA minimal medium (Fig. 1). Here, the PGA also plays the role of an inducer of virulence factors synthesis (e.g., pectinolytic enzymes), because it mimics the presence of a major plant cell wall component (Smadja et al. 2004a,b). Among them, only the $\mathrm{Pa}-\mathrm{QS}+$ strain produced the green fluorescence, overwhelming the blue one that constitutively labeled the two sensors. Thus, the kinetics of $\mathrm{GFP}_{\mathrm{ASV}}$ production followed the endogenous production of AHL by the $\mathrm{Pa}$ QS+ population. As expected, these kinetics correlated well with those of 3-oxo-C C $_{8}$-HSL synthesis and luxI synthase expression previously described in the CFBP6276 strain (Latour et al. 2007). Because the production of green fluorescence was restored in the $\mathrm{Pa}-\mathrm{QS}-$ strain when adding a weak concentration of AHL, $P a$-QS- could be used as both a control strain deprived of QS communication and a sensitive sensor of the occurrence of exogenous AHL. A similar approach was applied to obtain a dual-colored $R$. erythropolis able to monitor AHL detection and degradation. Here, the plasmid pEPR1 was used as the promoter-probe vector, because it was previously shown to be suitable for normalized measurements of promoter activities during bacterial growth, avoiding the influence of plasmid copy number variations on the promoter activity assay (Knoppová et al. 2007). Equipped with pEPR1-qsdR-Pqsd:: $g f p_{\mathrm{uv}}$-mcherry, a construct based on pEPR1, Re-QQ+ cells monitored a limiting induction value of approximately $1 \mu \mathrm{M} 3-$ oxo- $\mathrm{C}_{8}$-HSL. This value has ecological significance, because it is below the minimal active concentrations of AHL (i.e., threshold concentration) attributed to Pectobacterium QS (10 $\mu \mathrm{M})$ (Wirth et al. 1996). It is also lower than the values determined by previous measurements recorded in rotting tubers colonized by the $P$. atrosepticum SCRI1043 strain (i.e., $290 \mu \mathrm{M})$ (Liu et al. 2008) or of the same order $(2.5 \mu \mathrm{M})$ as that found in tubers colonized by the $\mathrm{Pa}-\mathrm{QS}+$ strain (Fig. 3A). Therefore, it was reasonable to assume that this sensitivity would be fully sufficient to detect biologically meaningful concentrations of AHL in situ.

When exposed to signaling molecules, most $R e-\mathrm{QQ}+$ cells changed from red to yellow fluorescence (Fig. 2). This change in fluorescence is explained by the action of AHLs which prevents the QsdR repressor from binding to the promoter region, inducing derepression of the $q s d$ cluster genes expression (Barbey et al. 2018). Color variation in fluorescence from amber to yellow revealed a heterogeneity of the GFP expression in the sensor population (Fig. 2). Such a phenomenon was also observed for dual-colored cells exhibiting a high variability in the expression of the GFP-based reporter in microcolonies (Rochat et al. 2010). It is well known that the clonal cell populations exhibit substantial phenotypic variation, often under the control of nonlinear mechanisms for intercellular communication (Shapiro 2007). These variations are related to transcription rate, regulatory dynamics, and genetic factors that control the amplitude of gene expression and fluctuations in cellular components (Elowitz et al. 2002). Consequently, when a gene encoding the fluorescent protein was weakly expressed in a dual-tagged strain, the ratio of the two fluorescences varied in the cells of the same population, indicating a heterogeneity of the expression of the gene from individual to individual. This is the case for the $R e-\mathrm{QQ}+$ sensor, in which the expression of one of the reporter genes is directed by a strong constitutive promoter and that of the other one by an inducible promoter.

Pectinolytic bacteria penetrate tubers using wounds or natural openings (e.g., lenticels). This primary invasion is supported by the plant-soluble sugars and by the cellular contents released at the level of the wound (Hélias et al. 2000; Hugouvieux-Cotte-Pattat 2016). During this colonization phase, a repression of the expression of virulence factor expression allows the bacteria to invade their host without being hindered by the plant defense response (Mäe et al. 2001; Toth et al. 2004). This first step is followed by a symptomatic stage beginning with a synchronized and massive release of PCWDEs. The burst of extracellular enzymes is responsible for a bacterial metabolic change inducing plant tissue degradation and the subsequent invasion (Hugouvieux-Cotte-Pattat 2016). The natural colonization of potato organs by pectinolytic pathogens after vacuum infiltration from leaves or tubers was precisely visualized by Robert Czajkowski during a prolix $\mathrm{Ph} . \mathrm{D}$. thesis, taking advantage of the huge potential of CLSM by using fluorescent protein-tagged strains (Czajkowski et al. 2010a,b, 2011). In our study, we deeply wounded the tuber with a strong inoculum in order to promote a rapid invasion and rotting symptoms. Nevertheless, these drastic conditions allowed the pathogenic cycle to be preserved; the primary invasion phase took place in approximately 2 days, after which the soft rot phase was observed (Fig. 3). The transitional step, in which the cellular quorum has just been reached and which separates the two phases of the disease, was selected for initial plant tissue investigations. Indeed, this step is susceptible to harboring crucial molecular interactions leading to the appearance of damage. We designed a sensitive $\mathrm{Pa}-\mathrm{QS}+$ reporter which enabled the visualization of cell-to-cell communication at both the single-cell and microcolony level within the potato tuber. Interestingly, using $P$. putida reporters producing or monitoring AHL, Gantner et al. (2006) observed that AHLbased communication occurs not only within dense populations but also in very small groups or individual bacteria on tomato roots. Moreover, they noted that a single cell represents a sufficient quorum to produce and excrete enough signaling molecules for it to communicate with and activate lux gene expression in neighboring cells. CLSM images revealed that $P$. atrosepticum cells are mainly located on the pith cell walls 2 dpi. They form active clusters embedded in cell wall components, leading to multiple walls breaking. This confirms the preferential affinity of these bacteria for cell wall structures and the onset of an intense hydrolytic activity that can explain macroscopic damage to the tuber a few days later (Fig. 3). Because most $\mathrm{Pa}$-QS+ cells produce a bright-green fluorescence, it is assumed that QS plays an important role in the population interactions or catabolic activities that take place within these microcolonies. These observations are in agreement with the "efficiency sensing" and "cluster sensing" concepts, suggesting that bacteria use QS to sense their neighbors belonging to a microcolony in an open environment, to improve the efficiency of their metabolism (Hense et al. 2007; Platt and Fuqua 2010).

The potato tuber represents a strategic challenge for the nutrition of the future world's population (FAO 2008). Because seed tubers are a source and vector of the inoculum, and because no chemical control of the pathogen exists, disease prevention methods are limited to sanitary measures, avoiding the wounding of tubers, and the use of certified seed tubers excluding the most sensitive cultivars (Janse and Wenneker 2002). In addition, there are attempts to establish smart biocontrol treatments that both are respectful of the microbial balance and limit the development of microbial resistance (Bais 2012; 
Dessaux et al. 2016; Diallo et al. 2011; Latour 2016). Among them, the QQ approach aims at reducing virulence expression rather than limiting cell growth or eradicating pathogens (Dong et al. 2001; Grandclément et al. 2016). The control of $P$. atrosepticum by $R$. erythropolis was investigated by coinoculating potato tubers with $\mathrm{Pa}-\mathrm{QS}+$ and $R e-\mathrm{QQ}+$ sensors. $\mathrm{Pa}$ $\mathrm{QS}+$ (or its luxI derivative, $P a$-QS-) and $R e-\mathrm{QQ}+$ strains grew in mixed populations, confirming that $R$. erythropolis $\mathrm{R} 138$ did not express antibiotic activities against $P$. atrosepticum CFBP6276 (Kwasiborski et al. 2015). In addition, the dualcolored $\mathrm{Pa}-\mathrm{QS}+, \mathrm{Pa}-\mathrm{QS}-$, and $\mathrm{Re}-\mathrm{QQ}+$ exhibited growth characteristics in potato tubers similar to the wild-type CFBP6276 and R138 strains, respectively (Barbey et al. 2013, 2018). This indicates that the bacterial growth was affected by neither the presence of the pME6000 or pEPR1 plasmids nor the production of fluorescent proteins. This vitality is also perceptible with the observation of rod-shaped $R e-\mathrm{QQ}+$ cells. Indeed, in $R$. erythropolis, this form is associated with metabolic active and replicating cells (including their extrachromosomal material) in contrast to cocci cells (Singhi et al. 2016). As expected, the AHL-controlled virulence functions were effectively reduced by coinoculation with the biocontrol agent responsible for the reduction in the maceration of tuber tissues (Fig. 3 versus Fig. 4). The QQ monitoring was done by using the previously described transcriptional regulatory mechanism of the qsd pathway. Expression of the $q s d$ operon was shown to be induced when the pathogen quorum was reached and to require the presence of the AHL signal. This induction by AHL signals was confirmed in this work by images revealing quenching cells only in the vicinity of pathogen cells producing AHL. This coupling is strongly present in microcolonies mixing high densities of both cell types (yellow hot spots) attached to the parenchymal cell walls (Fig. 4). In contrast, no quenching cells were identified thus far from $\mathrm{Pa}$-QS+ or near the $\mathrm{Pa}$-QS- QS-deficient pathogen, even in the context of microcolonies (Fig. 5). The high bacterial density as well as the intense and concomitant QS and QQ activities suggest that hot spots support a metabolic competition between the pathogen and the biocontrol agent; for example, for the organic sulfur uptake. This hypothesis is supported by a previous work comparing the transcriptome of $R$. erythropolis R138 in the presence of $P$. atrosepticum CFBP6276 or its QSdeficient alter ego (Kwasiborski et al. 2015) and by other works demonstrating the significant role of methionine metabolism in P. atrosepticum virulence and the synthesis of its AHLs (Crépin et al. 2012a; Cubitt et al. 2013). Thus, in a mixed-population context, tuber sulfur resources serve for AHL synthesis by the pathogen, whereas AHL could represent a nutrient source for rhodococci.

In conclusion, the generated biosensors appear to be complementary tools with a tremendous potential. The ability to monitor endogenous or exogenous AHL synthesis at the cellular level enables us to investigate cell-to-cell communication and intercellular signal transduction throughout the hostpathogen interaction. Monitoring AHL degradation contributes to the understanding of cellular metabolism, microbe-microbe interaction, and communication interference. As an initial trial, we obtained direct visual evidence for AHL production, detection, and degradation in the tuber battlefield. QS and QQ activities appear to be strongly collocated in contact with the plant cell wall, mediating a cometabolism whose outcome leads to disease or biocontrol. This is the first report imaging a QQ action at both the single-cell and microcolony levels.

Table 1. Bacterial strains and plasmids

\begin{tabular}{|c|c|c|}
\hline Strain or plasmid & Relevant characteristics ${ }^{\mathbf{a}}$ & Source or reference \\
\hline \multicolumn{3}{|l|}{ Escherichia coli } \\
\hline Top 10 & $\begin{array}{l}\text { Competent cells; F- mcrA } \Delta(m r r-h s d \mathrm{RMS}- \\
\text { mcrBC) } \Phi 80 \text { lacZ } \mathrm{M} 15 \Delta \text { lacX74 rec } \mathrm{A} 1 \\
\text { araD139 } \Delta(\text { araleu }) 7697 \text { galU galK } r p s \mathrm{~L} \\
\text { (StrR) end } \mathrm{A} 1 \text { nup } \mathrm{G}\end{array}$ & Lab collection \\
\hline \multicolumn{3}{|l|}{ Rhodococcus erythropolis } \\
\hline $\mathrm{R} 138$ & $\begin{array}{l}\text { AHL-degrading isolate obtained from } \\
\text { hydroponic culture of potato plants }\end{array}$ & Cirou et al. 2007 \\
\hline $\begin{array}{l}\left.\mathrm{R} 138 \text { (pEPR1-qsdR-Pqsd::gfp } p_{\mathrm{uv}}-m c h e r r y\right) \\
\quad(\operatorname{ReQQ}+)\end{array}$ & $\begin{array}{l}\mathrm{R} 138 \text { strain transformed by } \mathrm{pEPR} 1 \\
\text { qsdR-P } q s d:: g f p_{u v}-\text { mcherry; } \mathrm{Km}^{\mathrm{r}}\end{array}$ & Barbey et al. 2018 \\
\hline \multicolumn{3}{|l|}{ Pectobacterium atrosepticum } \\
\hline $\begin{array}{l}6276 \\
6276-\mathrm{EI}\end{array}$ & $\begin{array}{l}\text { Potato soft rot pathogen, AHL producer } \\
\text { expI mutant derivative of CFBP } 6276 \text { strain; } \\
\mathrm{Gm}^{\mathrm{r}}\end{array}$ & $\begin{array}{l}\text { Strain CFBP, Smadja et al. 2004a } \\
\text { Latour et al. } 2007\end{array}$ \\
\hline $\begin{array}{l}6276\left(\mathrm{pME} 6000-l u x R-\mathrm{P}_{\text {luxl }}: \because g f p-c f p\right) \\
\quad(P a-\mathrm{QS}+)\end{array}$ & $\begin{array}{l}\text { CFBP } 6276 \text { strain transformed by pME6000- } \\
\text { luxR }-\mathrm{P}_{\text {luxI }}: \text { :gfp-cfp; } \mathrm{Tc}^{\mathrm{r}}\end{array}$ & This study \\
\hline $\begin{array}{l}\left.\text { 6276-EI (pME6000-luxR-P } \mathrm{P}_{\text {luxI }} \because: g f p-c f p\right) \\
\quad(\text { Pa-QS-) }\end{array}$ & $\begin{array}{l}\text { expI mutant derivative of CFBP } 6276 \text { strain } \\
\text { transformed by pME6000-luxR- } \mathrm{P}_{\text {lux }}: \because g f p \text { - } \\
c f p ; \mathrm{Tc}^{\mathrm{r}}\end{array}$ & This study \\
\hline \multicolumn{3}{|c|}{ Ji } \\
\hline pME6000 & $\begin{array}{l}\text { Cloning vector, derivative of pVS1, low } \\
\text { copy; } \mathrm{Tc}^{\mathrm{r}}\end{array}$ & Maurhofer et al. 1998 \\
\hline pME6000 luxR $-\mathrm{P}_{\text {luxI }}: \because g f p_{a s v}-c f p$ & $\begin{array}{l}\text { pME6000-cfp with a } \mathrm{P}_{\text {luxI }} \because: g f p_{\text {asv }} \\
\text { transcriptional fusion under the control of } \\
\text { luxR expression; } \mathrm{Tc}^{\mathrm{r}}\end{array}$ & This study \\
\hline pJBA 89 & $\begin{array}{l}\mathrm{pUC} 18 \mathrm{Not}-l u x R-P_{\text {lux }} \text {-RBSII- } g f p(\mathrm{ASV})-\mathrm{T}_{0^{-}} \\
\mathrm{T}_{1} ; \mathrm{Ap}^{\mathrm{r}}\end{array}$ & Andersen et al. 2001 \\
\hline pPSV35-mCherry & $\begin{array}{l}\text { pPSV35 vector containing a mCherry } \\
\text { cassette under constitutive promoter; } \mathrm{Gm}^{\mathrm{r}}\end{array}$ & Lab collection \\
\hline pEPR1 & $\begin{array}{l}\text { Shuttle promoter-probe vector carrying the } \\
\text { promoterless } g f p_{\mathrm{uv}} \text { reporter gene; } \mathrm{Km}^{\mathrm{r}}\end{array}$ & Knoppová et al. 2007 \\
\hline pEPR1-qsdR-P $q s d:: g f p_{\mathrm{uv}}-m c h e r r y$ & $\begin{array}{l}\text { pEPR1-mcherry with a Pqsd::gfp } \\
\text { transcriptional fusion under the control of } \\
\text { QsdR; } \mathrm{Km}^{\mathrm{r}}\end{array}$ & Barbey et al. 2018 \\
\hline
\end{tabular}

${ }^{\mathrm{a}} \mathrm{Km}^{\mathrm{r}}, \mathrm{Ap}^{\mathrm{r}}, \mathrm{Gm}^{\mathrm{r}}$, and $\mathrm{Tc}^{\mathrm{r}}$ indicate resistance to kanamycin, apramycin, gentamycin, and tetracycline, respectively. AHL $=N$-acyl homoserine lactone and CFBP = Collection Française de Bactéries associées aux Plantes, Institut National de la Recherche Agronomique, Angers, France. 


\section{MATERIALS AND METHODS}

Bacterial strains, growth, and culture conditions.

P. atrosepticum strain CFBP6276 was isolated from Solanum tuberosum (Smadja et al. 2004b). It causes blackleg of the stem and a strong tuber soft rot in this host, justifying its use as a phytopathogen model (Crépin et al. 2012b). Its virulence was demonstrated to be QS proficient (Smadja et al. 2004a). The QS signal molecules detected in this strain were the $N$-(3-oxooctanoyl)-L-homoserine lactone (3-oxo- $\mathrm{C}_{8}$-HSL) as the major AHL as well as low but detectable levels of $N$-octanoyl-Lhomoserine lactone, $N$-3-oxo-hexanoyl-L-homoserine lactone, and $N$-3-oxo-decanoyl-L-homoserine lactone (Crépin et al. 2012a). The strain R138 was isolated from the potato rhizosphere, in which it efficiently degrades AHLs (Barbey et al. 2013; Cirou et al. 2011b). The R138 genome (6.7 Mbp) was sequenced recently (Kwasiborski et al. 2013, 2015). A single circular chromosome carries the qsd operon and the upstream $q s d R$ gene encoding a transcriptional repressor (Barbey et al. 2018).

The characteristics of bacterial strains and plasmids used are presented in Table 1. P. atrosepticum CFBP 6276 and Escherichia coli strains were cultivated in PGA minimal medium supplemented with $0.4 \%$ polygalacturonic acid (wt/vol) (SigmaAldrich), as described elsewhere (Smadja et al. 2004a), and Luria-Bertani (LB) medium (AES Chemunex), respectively. $R$. erythropolis strains were cultivated in $7 \mathrm{H} 9$ minimal medium (Difco) supplemented with hexanoate at $6 \mathrm{mM}$ (Sigma-Aldrich) as the sole carbon source for transcriptional fusion assays and for the inoculation of potato tubers. When necessary, growth media were supplemented with kanamycin at a concentration of 30 $\mu \mathrm{g} / \mathrm{ml}$ for $E$. coli and $200 \mu \mathrm{g} / \mathrm{ml}$ for $R$. erythropolis, with tetracycline at $10 \mu \mathrm{g} / \mathrm{ml}$ and gentamycin at $30 \mu \mathrm{g} / \mathrm{ml}$ for $P$. atrosepticum, with ampicillin at $100 \mu \mathrm{g} / \mathrm{ml}$ for $E$. coli and solidified with agar $(15 \mathrm{~g} /$ liter $)$. All strains were grown on a rotary shaker (180 rpm) at $25^{\circ} \mathrm{C}$ for $R$. erythropolis and P. atrosepticum strains and $37^{\circ} \mathrm{C}$ for E. coli. Growth was monitored spectrophotometrically at $580 \mathrm{~nm}$. All cultures were inoculated at an initial optical density at $580 \mathrm{~nm}$ of 0.05 .

\section{Construction of pectobacterial and rhodococcal biosensors.}

All polymerase chain reactions (PCR) were performed with Phusion Hi-Fidelity polymerase (Biolabs NEB) in accordance with the supplier's recommendations. The pME6000 vector designed by Maurhofer and coworkers (1998) was used to tag P. atrosepticum cells and monitor the occurrence of AHL. As the fluorophore, we used the CFP, a mutant of GFP originally isolated from the jellyfish Aequorea victoria (Andersen et al. 1998, 2001), to tag both $P$. atrosepticum strains. The 753-bp cfp open reading frame was amplified using cfp_F and cfp_R primers and cloned into pME6000 vector downstream of the $\mathrm{Plac}_{U V 5}$ promoter after digestion by the XhoI and ClaI restriction enzymes. This promoter allows the constitutive expression of the $c f p$ gene. To investigate QS activity, the sequence
luxR $-\mathrm{P}_{\text {lux } I}: \because g p_{A S V}$ was amplified from the pJBA89 plasmid by PCR using the asv_F and asv_R primers (Charlesworth et al. 2015). After digestion with $S a c I$ and SpeI restriction enzymes, the 2.5-kbp PCR product was cloned into the pME6000-cfp vector. After sequencing the cloned regions, the resulting pME6000-luxR-P $\mathrm{P}_{l u x I}: g f p$-cfp vector was introduced into the $P$. atrosepticum CFBP 6276 wild-type and expI-deficient mutant cells by electroporation as follows: $100 \mu \mathrm{l}$ of electrocompetent bacterial cells were mixed with $200 \mathrm{ng}$ of plasmid DNA and electroshocked at $18 \mathrm{kV} / \mathrm{cm}$ using a Savant electroporator (Thermo Fischer Scientific). After electroporation, bacterial cells were cultivated in $1 \mathrm{ml}$ of $\mathrm{LB}$ broth for $2 \mathrm{~h}$ with shaking (180 rpm) and plated on LB agar containing tetracycline. Positives clones were checked by PCR.

The pEPR1 promoter probe vector (Knoppová et al. 2007) carries the promoterless $g f p_{\text {uv }}$ gene encoding a highly sensitive fluorophore. The GFPuv protein emits more fluorescence than the wild-type form, because it is more hydrophilic and, therefore, more soluble in the bacterium than the original GFP (Battistutta et al. 2000; Crameri et al. 1996). This probe vector was modified by introducing an mCherry (a variant of red fluorescent protein DsRed isolated from sea anemone Discosoma) cassette to constitutively tag rhodococcal cells and a $q s d R-\mathrm{P} q s d:: g f p_{u v}$ transcriptional fusion to monitor QQ activity (Barbey et al. 2018). The mCherry cassette was amplified with the primers mCherry_F and mCherry_R (Table 2) from the pPSV35-mCherry plasmid DNA and cloned into pEPR1 after NheI digestion. The $q s d R-\mathrm{P} q s d$ DNA fragment containing the $q s d R$ gene and the $q s d$ promoter was introduced into the pEPR1-mCherry after PCR amplification using the primers qsdR-Pqsd_F and qsdR-Pqsd_R (Table 2) and digestion by NsiI and $B a m \mathrm{HI}$. The resulting pEPR1-qsdR-P $q s d:: g f p_{u v}$-mCherry vector was introduced into the $R$. erythropolis $\mathrm{R} 138$ cells by electroporation, as previously described (Barbey et al. 2013).

\section{Transcriptional fusion assays.}

To check the induction of $g f p$ reporter gene transcription by AHLs, the pectobacterial pME6000-luxR- $\mathrm{P}_{l u x I}: \because g f p-c f p$ biosensor strains ( $P a-Q S+$ or $P a-Q S-)$ and the rhodococcal pEPR1-qsdR-P $q s d:: g f p_{\mathrm{uv}}-m$ Cherry biosensor strain (Re-QQ+) were cultivated in PGA minimal medium and $7 \mathrm{H} 9$ minimal medium supplemented with $6 \mathrm{mM}$ hexanoate, respectively. At the midexponential growth phase, 3 -oxo- $\mathrm{C}_{8}$ - $\mathrm{HSL}$ was added to induction condition cultures that were incubated with control cultures at $25^{\circ} \mathrm{C}$, with shaking for $15 \mathrm{~h}$. This inducer 3-oxo- $\mathrm{C}_{8^{-}}$ $\mathrm{HSL}$ was tested at a final concentration of $10 \mathrm{nM}$ and $1 \mu \mathrm{M}$ for pectobacterial and rhodococcal biosensors, respectively. Bacterial cells were harvested every $2 \mathrm{~h}$ for confocal microscopy analysis. Three bacterial smears from three different cultures were analyzed for each condition.

Biocontrol assays on potato tubers.

Overnight cultures of $P$. atrosepticum CFBP6276 (Pa-QS+ or $\mathrm{Pa}$-QS-) and $R$. erythropolis $\mathrm{R} 138$ ( $R e-\mathrm{QQ}+)$ were washed in

Table 2. Primers used for biosensor construction

\begin{tabular}{ll}
\hline Primer name & \multicolumn{1}{c}{ Sequence $^{\mathbf{a}^{\mathbf{2}}}$} \\
\hline cfp_F & \\
cfp_R & $5^{\prime}$ ATTATTCTCGAGGGAATTGTGAGCGGATAACA 3' \\
asv_F & $5^{\prime}$ ATTATTATCGATTTACTTACTTACTTATATAATTCATCCATTC 3' \\
asv_R & $5^{\prime}$ TAATAAGAGCTCTTTATGCTTCCGGCTCGTAT 3' \\
mCherry_F & $5^{\prime}$ TAATAAACTAGTGCTAGCTTGGATTCTCACCAA 3' \\
mCherry_R & $5^{\prime}$ AATACACTGCCCGTTTCAGG 3' \\
qsdR-Pqs_F & $5^{\prime}$ TAATAAGCTAGCGAATCTTATTTGTAGAGTTCATCCA 3' \\
qsdR_Pqsd_R & $5^{\prime}$ TAATAAATGCATTGCGAAGTGTGATCCTGTG 3' \\
\hline
\end{tabular}

\footnotetext{
${ }^{a}$ All oligonucleotides used in this study were synthesized by Eurogentec. Restriction sites are indicated in italics.
} 
$0.9 \% \mathrm{NaCl}$. S. tuberosum 'Allians' tubers were prepared for inoculations as previously described (Barbey et al. 2013). They were inoculated by injection into the intramedulla (to a depth of $1 \mathrm{~cm}$ ) with $10 \mu \mathrm{l}$ of a cell suspension containing $10^{7} \mathrm{CFU}$ of $\mathrm{Pa}$ QS+ per inoculation site (positive control of tuber soft rot) or the following bacterial combinations: $10^{7} \mathrm{CFU}$ of $\mathrm{Pa}-\mathrm{QS}+$ with $10^{7} \mathrm{CFU}$ of $\mathrm{Re}-\mathrm{QQ}+$ or $10^{7} \mathrm{CFU}$ of $\mathrm{Pa}-\mathrm{QS}-$ with $10^{7} \mathrm{CFU}$ of $R e-\mathrm{QQ}+$ per inoculation site. For controls, the suspensions of $P a$-QS+, $P a-Q S-$, or $R e-\mathrm{QQ}+$ were replaced with $0.9 \% \mathrm{NaCl}$. The inoculated tubers were incubated in a Minitron incubator (Infors) at $25^{\circ} \mathrm{C}$ with a relative humidity of $80 \%$. At 1,2 , and 7 days, five tubers for each condition were sectioned across the middle, photographed, analyzed by measuring the maceration diameter, and cut for microscopy or bacterial population analysis. These experiments were conducted three times at different times of the year. The Mann and Whitney test was used to assess differences in maceration symptoms between the groups $(\alpha=0.05)$.

\section{Analysis of bacterial populations collected from inoculated potato tubers.}

Bacterial population analysis was carried out as described previously (Barbey et al. 2013), with the following modifications. Bacterial populations were counted on tryptone yeast extract medium supplemented with 5-bromo-4-chloro-3indolyl- $\beta$-D-galactoside ( $40 \mu \mathrm{g} / \mathrm{ml}$; Promega Corp.). After 2 days of incubation at $25^{\circ} \mathrm{C}, R$. erythropolis $\mathrm{R} 138$ appeared as white colonies, whereas $P$. atrosepticum CFBP 6276 and its expI-derivative strain appeared as blue colonies. Three independent experiments were performed and, for each experiment, three independent samples were analyzed for each condition.

\section{Quantification of AHL from potato tubers.}

For each condition, AHL were extracted from three samples of three different potato tubers. Samples of $500 \mathrm{mg}$ of tuber (fresh weight) were collected to extract AHL as described by Barbey et al. (2013). Reported values are means \pm standard deviation of three independent experiments.

\section{EM observation of tuber colonization patterns and QS versus $Q Q$ activities.}

Potato tubers to be analyzed were cut into slices $0.3 \mathrm{~cm}$ thick, then placed in a Petri dish for EM analysis. EM was performed using a Zeiss inverted microscope (Axio-Vert.A1 FL-LED; Carl Zeiss MicroImaging) and Zeiss filter sets for GFP and mCherry observation (filter GFP = excitation, $470 \mathrm{~nm}$; emission, $525 \mathrm{~nm}$; green channel and filter mCherry = excitation, $560 \mathrm{~nm}$; emission, $630 \mathrm{~nm}$; red channel). Tuber slices were observed with a $\times 10$ objective lens. Images of dual-colored cells were combined using Q-Capture Pro 7 software.

\section{CLSM observation of biosensors growth kinetic, tuber colonization patterns, and QS versus QQ activities.}

All microscopic observations and image acquisitions for biosensor activity analysis were performed using an LSM 710 scanning confocal microscope (Carl Zeiss MicroImaging). To investigate $g f p$ induction by AHLs, bacterial smears were performed from $\mathrm{Pa}-\mathrm{QS}+, \mathrm{Pa}-\mathrm{QS}-$, and $R e-\mathrm{QQ}+$ biosensor cultures with or without AHLs. They were fixed with ethanol and squashed between the slide and coverslip before microscopy analysis. For QS and QQ activity analysis in potato tubers, tubers were diced in cubes approximately $0.5 \mathrm{~cm}$ on a side and fixed for $1.5 \mathrm{~h}$ in a $4 \%$ paraformaldehyde (Alfa Aesar) and $0.2 \%$ glutaraldehyde (Sigma-Aldrich) mixture. Samples were washed three times for $5 \mathrm{~min}$ in phosphate-buffered saline. After drying, tissues were embedded in tissue-freezing medium (OCT for optimal cutting temperature; Leica) and frozen at $-80^{\circ} \mathrm{C}$. Thin sections of $7 \mu \mathrm{m}$ were prepared with a microtomecryostat (Thermo Shandon Cryotome SME Cryostat) and examined by CLSM with the following excitation and emission wavelengths: GFP (excitation, $488 \mathrm{~nm}$; emission, $509 \mathrm{~nm}$; green channel), mCherry (excitation, $543 \mathrm{~nm}$; emission, 610 $\mathrm{nm}$; red channel), and CFP (excitation, $405 \mathrm{~nm}$; emission, 477 $\mathrm{nm}$; blue channel). Bacterial smears and tuber thin sections were observed using a $\times 63$ oil-immersion objective. Confocal images were acquired with Zen 2009 software (Carl Zeiss MicroImaging) using the same gains and offset parameters for all images. Experiments were replicated at least three times and representative samples are shown.

\section{ACKNOWLEDGMENTS}

We thank B. Burns (University of New South Wales, School of Biotechnology and Biomolecular Sciences and Australian Centre for Astrobiology, Sydney 2052, Australia) for her kind provision of the pJBA89 plasmid, D. Haas (emeritus Professor in Department of Fundamental Microbiology, University of Lausanne, Switzerland) for his kind provision the pME6000 plasmid, and B. Watson-Jones for linguistic support.

\section{LITERATURE CITED}

Afriat, L., Roodveldt, C., Manco, G., and Tawfik, D. S. 2006. The latent promiscuity of newly identified microbial lactonases is linked to a recently diverged phosphotriesterase. Biochemistry 45:13677-13686.

Andersen, J. B., Heydorn, A., Hentzer, M., Eberl, L., Geisenberger, O., Christensen, B. B., Molin, S., and Givskov, M. 2001. gfp-Based N-acyl homoserine-lactone sensor systems for detection of bacterial communication. Appl. Environ. Microbiol. 67:575-585

Andersen, J. B., Sternberg, C., Poulsen, L. K., Bjorn, S. P., Givskov, M., and Molin, S. 1998. New unstable variants of green fluorescent protein for studies of transient gene expression in bacteria. Appl. Environ. Microbiol. 64:2240-2246.

Bais, H. P. 2012. Shoot the messages not the messengers. Plant Soil 358: 7-10.

Barbey, C., Chane, A., Burini, J.-F., Maillot, O., Merieau, A., Gallique, M., Beury-Cirou, A., Konto-Ghiorghi, Y., Feuilloley, M., Gobert, V., and Latour, X. 2018. A rhodococcal transcriptional regulatory mechanism detects the common lactone ring of AHL quorum-sensing signals and triggers the quorum-quenching response. Front. Microbiol. 9:2800.

Barbey, C., Crépin, A., Bergeau, D., Ouchiha, A., Mijouin, L., Taupin, L., Orange, N., Feuilloley, M., Dufour, A., Burini, J. F., and Latour, X. 2013 In Planta biocontrol of Pectobacterium atrosepticum by Rhodococcus erythropolis involves silencing of pathogen communication by the rhodococcal gamma-lactone catabolic pathway. PLoS One 8:e66642.

Barnard, A. M. L., and Salmond, G. P. C. 2007. Quorum sensing in Erwinia species. Anal. Bioanal. Chem. 387:415-423.

Battistutta, R., Negro, A., and Zanotti, G. 2000. Crystal structure and refolding properties of the mutant F99S/M153T/V163A of the green fluorescent protein. Proteins 41:429-437.

Bell, K. S., Philp, J. C., Aw, D. W. J., and Christofi, N. 1998. The genus Rhodococcus. J. Appl. Microbiol. 85:195-210.

Bloemberg, G. V. 2007. Microscopic analysis of plant-bacterium interactions using auto fluorescent proteins. Eur. J. Plant Pathol. 119:301-309.

Burr, T., Barnard, A. M. L., Corbett, M. J., Pemberton, C. L., Simpson, N. J. L., and Salmond, G. P. C. 2006. Identification of the central quorum sensing regulator of virulence in the enteric phytopathogen, Erwinia carotovora: The VirR repressor. Mol. Microbiol. 59:113-125.

Cha, C., Gao, P., Chen, Y. C., Shaw, P. D., and Farrand, S. K. 1998. Production of acyl-homoserine lactone quorum-sensing signals by gram-negative plant-associated bacteria. Mol. Plant-Microbe Interact. 11:1119-1129.

Chalfie, M., Tu, Y., Euskirchen, G., Ward, W. W., and Prasher, D. C. 1994. Green fluorescent protein as a marker for gene expression. Science 263:802-805.

Charkowski, A., Blanco, C., Condemine, G., Expert, D., Franza, T., Hayes, C., Hugouvieux-Cotte-Pattat, N., López Solanilla, E., Low, D., Moleleki, L., Pirhonen, M., Pitman, A., Perna, N., Reverchon, S., Rodríguez Palenzuela, P., San Francisco, M., Toth, I., Tsuyumu, S., van der Waals, J., van der Wolf, J., Van Gijsegem, F., Yang, C. H., and Yedidia, I. 2012. The role of secretion systems and small molecules in soft-rot Enterobacteriaceae pathogenicity. Annu. Rev. Phytopathol. 50:425-449.

Charlesworth, J., Kimyon, O., Manefield, M., and Burns, B. P. 2015. Detection and characterization of $\mathrm{N}$-acyl-1-homoserine lactones using 
GFP-based biosensors in conjunction with thin-layer chromatography. J. Microbiol. Methods 118:164-167.

Christensen, L. D., van Gennip, M., Jakobsen, T. H., Givskov, M., and Bjarnsholt, T. 2011. Imaging $N$-acyl homoserine lactone quorum sensing in vivo. Methods Mol. Biol. 692:147-157.

Cirou, A., Diallo, S., Kurt, C., Latour, X., and Faure, D. 2007. Growth promotion of quorum-quenching bacteria in the rhizosphere of Solanum tuberosum. Environ. Microbiol. 9:1511-1522.

Cirou, A., Mondy, S., An, S., Charrier, A., Sarrazin, A., Thoison, O., DuBow, M., and Faure, D. 2011a. Efficient biostimulation of native and introduced quorum-quenching Rhodococcus erythropolis populations is revealed by a combination of analytical chemistry, microbiology, and pyrosequencing. Appl. Environ. Microbiol. 78:481-492.

Cirou, A., Raffoux, A., Diallo, S., Latour, X., Dessaux, Y., and Faure, D. 2011b. Gamma-caprolactone stimulates growth of quorum-quenching Rhodococcus populations in a large-scale hydroponic system for culturing Solanum tuberosum. Res. Microbiol. 162:945-950.

Crameri, A., Whitehorn, E. A., Tate, E., and Stemmer, W. P. C. 1996 Improved green fluorescent protein by molecular evolution using DNA shuffling. Nat. Biotechnol. 14:315-319.

Crépin, A., Barbey, C., Beury-Cirou, A., Hélias, V., Taupin, L., Reverchon, S., Nasser, W., Faure, D., Dufour, A., Orange, N., Feuilloley, M., Heurlier, K., Burini, J.-F., and Latour, X. 2012a. Quorum sensing signaling molecules produced by reference and emerging soft-rot bacteria (Dickeya and Pectobacterium spp.). PLoS One 7:e35176.

Crépin, A., Barbey, C., Cirou, A., Tannières, M., Orange, N., Feuilloley, M. Dessaux, Y., Burini, J.-F., Faure, D., and Latour, X. 2012b. Biological control of pathogen communication in the rhizosphere: A novel approach applied to potato soft rot due to Pectobacterium atrosepticum. Plant Soil 358: 27-37.

Cubitt, M. F., Hedley, P. E., Williamson, N. R., Morris, J. A., Campbell, E., Toth, I. K., and Salmond, G. P. C. 2013. A metabolic regulator modulates virulence and quorum sensing signal production in Pectobacterium atrosepticum. Mol. Plant-Microbe Interact. 26:356-366.

Czajkowski, R., de Boer, W. J., van Veen, J. A., and van der Wolf, J. M. 2010a. Downward vascular translocation of a green fluorescent proteintagged strain of Dickeya sp. (biovar 3) from stem and leaf inoculation sites on potato. Phytopathology 100:1128-1137.

Czajkowski, R., de Boer, W. J., van Veen, J. A., and van der Wolf, J. M. 2011. Studies on the interaction between the biocontrol agent, Serratia plymuthica A30, and blackleg-causing Dickeya sp. (biovar 3) in potato (Solanum tuberosum). Plant Pathol. 61:677-688.

Czajkowski, R., de Boer, W. J., Velvis, H., and van der Wolf, J. M. 2010b. Systemic colonization of potato plants by a soilborne, green fluorescent protein-tagged strain of Dickeya sp. biovar 3. Phytopathology 100 134-142.

Czajkowski, R., Pérombelon, M., Jafra, S., Lojkowska, E., Potrykus, M., van der Wolf, J., and Sledz, W. 2015. Detection, identification and differentiation of Pectobacterium and Dickeya species causing potato blackleg and tuber soft rot: A review. Ann. Appl. Biol. 166:18-38.

de Carvalho, C. C., and da Fonseca, M. M. 2005. The remarkable Rhodococcus erythropolis. Appl. Microbiol. Biotechnol. 67:715-726.

Dessaux, Y., Grandclément, C., and Faure, D. 2016. Engineering the rhizosphere. Trends Plant Sci. 21:266-278

Diallo, S., Crépin, A., Barbey, C., Orange, N., Burini, J.-F., and Latour, X. 2011. Mechanisms and recent advances in biological control mediated through the potato rhizosphere. FEMS Microbiol. Ecol. 75:351-364.

Dong, Y. H., Wang, L. H., Xu, J. L., Zhang, H. B., Zhang, X. F., and Zhang, L. H. 2001. Quenching quorum-sensing-dependent bacterial infection by an $N$-acyl homoserine lactonase. Nature 411:813-817.

Elowitz, M. B., Levine, A. J., Siggia, E. D., and Swain, P. S. 2002 Stochastic gene expression in a single cell. Science 297:1183-1186.

El Sahili, A., Kwasiborski, A., Mothe, N., Velours, C., Legrand, P., Moréra S., and Faure, D. 2015. Natural guided genome engineering reveals transcriptional regulators controlling quorum-sensing signal degradation. PLoS One 10:e0141718.

FAO (Food and Agriculture Organization). 2008:Page 144 in: International Year of the Potato 2008, New Light on a Hidden Treasure. Food and Agriculture Organization of the United Nations, Rome.

Gantner, S., Schmid, M., Dürr, C., Schuhegger, R., Steidle, A., Hutzler, P. Langebartels, C., Eberl, L., Hartmann, A., and Dazzo, F. B. 2006. In situ quantitation of the spatial scale of calling distances and population density-independent $\mathrm{N}$-acylhomoserine lactone-mediated communication by rhizobacteria colonized on plant roots. FEMS Microbiol. Ecol 56:188-194.

Grandclément, C., Tannières, M., Moréra, S., Dessaux, Y., and Faure, D. 2016. Quorum quenching: Role in nature and applied developments. FEMS Microbiol. Rev. 40:86-116.
Hélias, V., Andrivon, D., and Jouan, B. 2000. Internal colonization pathways of potato plants by Erwinia carotovora ssp. atroseptica. Plant Pathol. 49:33-42.

Hense, B. A., Kuttler, C., Müller, J., Rothballer, M., Hartmann, A., and Kreft, J. U. 2007. Does efficiency sensing unify diffusion and quorum sensing? Nat. Rev. Microbiol. 5:230-239.

Hugouvieux-Cotte-Pattat, N. 2016. Metabolism and virulence strategies in Dickeya-host interactions. Prog. Mol. Biol. Transl. Sci. 142:93-129.

Jafra, S., Przysowa, J., Czajkowski, R., Michta, A., Garbeva, P., and van der Wolf, J. M. 2006. Detection and characterization of bacteria from the potato rhizosphere degrading $\mathrm{N}$-acyl-homoserine lactone. Can. J. Microbiol. 52:1006-1015.

Janse, J. D., and Wenneker, M. 2002. Possibilities of avoidance and control of bacterial plant diseases when using pathogen-tested (certified) ortreated planting material. Plant Pathol. 51:523-536.

Knoppová, M., Phensaijai, M., Veselý, M., Zemanová, M., Nešvera, J., and Pátek, M. 2007. Plasmid vectors for testing in vivo promoter activities in Corynebacterium glutamicum and Rhodococcus erythropolis. Curr. Microbiol. 55:234-239.

Kwasiborski, A., Mondy, S., Beury-Cirou, A., and Faure, D. 2013. Genome sequence of the Pectobacterium atrosepticum strain CFBP6276, causing blackleg and soft rot diseases on potato plants and tubers. Genome Announce. 1:e00374-13.

Kwasiborski, A., Mondy, S., Chong, T.-M., Barbey, C., Chan, K.-G., BeuryCirou, A., Latour, X., and Faure, D. 2015. Transcriptome of the quorum-sensing signal-degrading Rhodococcus erythropolis responds differentially to virulent and avirulent Pectobacterium atrosepticum. Heredity 114:476-484

Latour, X. 2016. Smart Biocontrol. French Patent (env. Soleau) number 571074 and Trademark number 16/4 288 066/12 August. National Institute of Industrial Property (INPI), French Patent and Trademark Office. BOPI number 16/32, vol. I.

Latour, X., Barbey, C., Chane, A., Groboillot, A., and Burini, J.-F. 2013. Rhodococcus erythropolis and its $\gamma$-lactone catabolic pathway: An unusual biocontrol system that disrupts pathogen quorum sensing communication. Agronomy (Basel, Switz.) 3:816-838.

Latour, X., Diallo, S., Chevalier, S., Morin, D., Smadja, B., Burini, J.-F., Haras, D., and Orange, N. 2007. Thermoregulation of $N$-acyl homoserine lactone-based quorum sensing in the soft rot bacterium Pectobacterium atrosepticum. Appl. Environ. Microbiol. 73:4078-4081.

Liu, H., Coulthurst, S. J., Pritchard, L., Hedley, P. E., Ravensdale, M., Humphris, S., Burr, T., Takle, G., Brurberg, M.-B., Birch, P. R. J., Salmond, G. P. C., and Toth, I. K. 2008. Quorum sensing coordinates brute force and stealth modes of infection in the plant pathogen Pectobacterium atrosepticum. PLoS Pathog. 4:e1000093.

Mäe, A., Montesano, M., Koiv, V., and Palva, E. T. 2001. Transgenic plants producing the bacterial pheromone $\mathrm{N}$-acyl-homoserine lactone exhibit enhanced resistance to the bacterial phytopathogen Erwinia carotovora. Mol. Plant-Microbe Interact. 14:1035-1042.

Maurhofer, M., Reimmann, C., Schmidli-Sacherer, P., Heeb, S., Haas, D., and Défago, G. 1998. Salicylic acid biosynthetic genes expressed in Pseudomonas fluorescens strain P3 improve the induction of systemic resistance in tobacco against tobacco necrosis virus. Phytopathology 88:678-684.

Papenfort, K., and Bassler, B. L. 2016. Quorum sensing signal-response systems in Gram-negative bacteria. Nat. Rev. Microbiol. 14:576-588.

Pátek, M., Eikmanns, B. J., Pátek, J., and Sahm, H. 1996. Promoters from Corynebacterium glutamicum: Cloning, molecular analysis and search for a consensus motif. Microbiology 142:1297-1309.

Pérombelon, M. C. M. 2002. Potato diseases caused by soft rot erwinias: An overview of pathogenesis. Plant Pathol. 51:1-12.

Phillips, G. J. 2001. Green fluorescent protein-A bright idea for the study of bacterial protein localization. FEMS Microbiol. Lett. 204:9-18.

Platt, T. G., and Fuqua, C. 2010. What's in a name? The semantics of quorum sensing. Trends Microbiol. 18:383-387.

Reverchon, S., and Nasser, W. 2013. Dickeya ecology, environment sensing and regulation of virulence programme. Environ. Microbiol. Rep. 5: 622-636.

Riedel, K., Hentzer, M., Geisenberger, O., Huber, B., Steidle, A., Wu, H. Høiby, N., Givskov, M., Molin, S., and Eberl, L. 2001. N-acylhomoserinelactone-mediated communication between Pseudomonas aeruginosa and Burkholderia cepacia in mixed biofilms. Microbiology 147:3249-3262.

Rochat, L., Péchy-Tarr, M., Baehler, E., Maurhofer, M., and Keel, C. 2010. Combination of fluorescent reporters for simultaneous monitoring of root colonization and antifungal gene expression by a biocontrol pseudomonad on cereals with flow cytometry. Mol. Plant-Microbe Interact. 23:949-961.

Schaefer, A. L., Val, D. L., Hanzelka, B. L., Cronan, J. E., Jr., and Greenberg, E. P. 1996. Generation of cell-to-cell signals in quorum 
sensing: Acyl homoserine lactone synthase activity of a purified Vibrio fischeri LuxI protein. Proc. Natl. Acad. Sci. U.S.A. 93:9505-9509.

Shapiro, J. A. 2007. Bacteria are small but not stupid: Cognition, natural genetic engineering and socio-bacteriology. Stud. Hist. Philos. Biol. Biomed. Sci. 38:807-819.

Singhi, D., Jain, A., and Srivastava, P. 2016. Localization of low copy number plasmid pRC4 in replicating rod and non-replicating cocci cells of Rhodococcus erythropolis PR4. PLoS One 11:e0166491.

Smadja, B., Latour, X., Faure, D., Chevalier, S., Dessaux, Y., and Orange, N. 2004a. Involvement of $N$-acylhomoserine lactones throughout plant infection by Erwinia carotovora subsp. atroseptica (Pectobacterium atrosepticum). Mol. Plant-Microbe Interact. 17:1269-1278.

Smadja, B., Latour, X., Trigui, S., Burini, J. F., Chevalier, S., and Orange, N. 2004b. Thermodependence of growth and enzymatic activities implicated in pathogenicity of two Erwinia carotovora subspecies (Pectobacterium spp.). Can. J. Microbiol. 50:19-27.
Steidle, A., Sigl, K., Schuhegger, R., Ihring, A., Schmid, M., Gantner, S., Stoffels, M., Riedel, K., Givskov, M., Hartmann, A., Langebartels, C., and Eberl, L. 2001. Visualization of $\mathrm{N}$-acylhomoserine lactonemediated cell-cell communication between bacteria colonizing the tomato rhizosphere. Appl. Environ. Microbiol. 67:5761-5770.

Toth, I. K., Newton, J. A., Hyman, L. J., Lees, A. K., Daykin, M., Ortori, C., Williams, P., and Fray, R. G. 2004. Potato plants genetically modified to produce $\mathrm{N}$-acylhomoserine lactones increase susceptibility to soft rot erwiniae. Mol. Plant-Microbe Interact. 17:880-887.

Veselý, M., Pátek, M., Nešvera, J., Cejková, A., Masák, J., and Jirků, V. 2003. Host-vector system for phenol-degrading Rhodococcus erythropolis based on Corynebacterium plasmids. Appl. Microbiol. Biotechnol. 61:523-527.

von Bodman, S. B., Bauer, W. D., and Coplin, D. L. 2003. Quorum sensing in plant-pathogenic bacteria. Annu. Rev. Phytopathol. 41:455-482.

Wirth, R., Muscholl, A., and Wanner, G. 1996. The role of pheromones in bacterial interactions. Trends Microbiol. 4:96-103. 